\title{
NEUROLOGICAL \\ PRACTICE \\ Epilepsy and Driving: A Survey of Canadian Neurologists
}

\author{
Richard S. McLachlan and Michael W. Jones
}

\begin{abstract}
Background: A seizure is the most common cause of loss of driving privileges for medical reasons but there is variability in how physicians and the authorities who regulate driving approach this issue. Methods: A questionnaire regarding epilepsy and driving was sent to all adult neurologists in Canada $(n=494)$. Results: Of $289(59 \%)$ neurologists responding, 50\% usually report patients with seizures to the department of motor vehicles compared to only $4 \%$ for stroke/TIA, $26 \%$ for dementia and $8 \%$ for other neurologic disorders $(\mathrm{p}<0.0001)$. In the five provinces with mandatory reporting laws, seizures were reported most of the time by $84 \%$ compared to only $19 \%$ in the five provinces with discretionary reporting ( $<<0.0001$ ). Nationwide, $44 \%$ agreed with mandatory reporting but this also differed in provinces with and without mandatory reporting legislation (63\% vs. 37\%, p < 0.0001). Only 49\% agreed with the current recommendation of at least one year seizure free interval before resuming driving. Conclusions: Seizures are disproportionately reported compared to other neurological conditions. Many neurologists disagree with the recommended Canadian standards for duration of driving restriction after seizures. Variability in the attitude and practice of neurologists in regard to reporting of seizures is confirmed.
\end{abstract}

RÉSUMÉ: Épilepsie et conduite automobile: enquête auprès des neurologues canadiens. Introduction: Une crise d'épilepsie est la cause la plus fréquente de la perte du permis de conduire pour des raisons médicales. Cependant, il existe une certaine variabilité dans la façon dont les médecins et les autorités qui réglementent la conduite automobile envisagent cette question. Méthode: Un questionnaire concernant l'épilepsie et la conduite a été envoyé à tous les neurologues qui traitent des adultes au Canada $(\mathrm{n}=494)$. Résultats: Parmi les 289 neurologues $(59 \%)$ qui ont répondu au questionnaire, $50 \%$ rapportent habituellement les patients qui ont des crises au département des véhicules automobiles comparé à seulement $4 \%$ pour l'AVC/ICT, $26 \%$ pour la démence et $8 \%$ pour les autres maladies neurologiques $(\mathrm{p}<0.0001)$. Dans les cinq provinces où la loi exige que ces patients soient rapportés, l'épilepsie était rapportée la plupart du temps par $84 \%$ des neurologues comparé à seulement $19 \%$ dans les cinq provinces où la déclaration est discrétionnaire $(\mathrm{p}<0.0001)$. À l'échelle canadienne, $44 \%$ étaient d'accord avec la déclaration obligatoire, mais l'opinion à ce sujet variait selon que les provinces avaient une législation sur la déclaration obligatoire ou pas (63\% vs. 37\%, p<0.0001). Seulement $49 \%$ étaient d'accord avec la recommandation actuelle qu'il y ait un intervalle d'un an sans crise avant que le permis ne soit accordé de nouveau. Conclusions: L'épilepsie est rapportée de façon disproportionnée par rapport aux autres maladies neurologiques. Plusieurs neurologues ne sont pas d'accord avec les standards canadiens recommandés au sujet de la durée de restriction de la conduite après la crise d'épilepsie. Nous confirmons la variabilité dans l'attitude et la pratique des neurologues dans la déclaration des crises d'épilepsie.

Can. J. Neurol. Sci. 1997; 24: 345-349

There are few issues that bring out more anxiety in both patient and physician than the possible loss of one's ability to operate a motor vehicle through illness or injury. The automobile has become synonymous with mobility, independence and modern living and driving is commonly considered to be a right rather than the privilege it is by law. Employment often depends on driving and in many parts of the country, there is a lack of public transportation so that inability to operate a motor vehicle is equivalent to a life of social isolation. For the physician, the support of a patient's welfare and the responsibility to the driving public can be difficult to reconcile when dealing with medical conditions that might potentially interfere with driving. The current legal climate dictates that physicians must not only focus on their traditional role of diagnosis and treatment but also must balance a position as patient advocate with that of unofficial representative of the state. In Canada, this balance is influenced considerably by the province of residence since provincial laws regarding driving vary particularly with respect to the physician's responsibility to report medical conditions which are potentially dangerous for the operation of a motor vehicle. This paper discusses some of these issues from a Canadian perspective and describes the opinion of neurologists across Canada in regard to epilepsy and driving.

\section{Methods}

Under the auspices of the Canadian League Against Epilepsy, all practising adult neurologists in Canada were sent a questionnaire in July, 1994 which asked about their approach to and

From the Department of Clinical Neurological Sciences, University of Western Ontario (R.S.M.); Department of Medicine (Neurology) University of British Columbia (M.WJ.)

RECEIVED DECEMBER 2, 1996. ACCEPTED IN FINAL FORM APRIL 24, 1997. Reprint requests to: Richard S. McLachlan, London Health Sciences Centre, University Campus, 339 Windermere Road, London, Ontario, Canada N6A 5A5 
and management of driving in patients with neurological disorders, particularly epilepsy. The questionnaires were anonymous and the eight questions were assessed by a statistician to make sure they were appropriate for Chi-square analysis using a statistical database. Since the two territories (Yukon and Northwest Territories) and one province (Prince Edward Island) did not have neurologists at the time of the survey, questionnaires were sent only to physicians practising in the nine other provinces. The location of the neurology practice was noted to allow comparison of data from provinces in which physician reporting is mandatory compared to those in which it is discretionary. At the time of the survey, it was mandatory for physicians to report patients with seizures and other medical conditions which might interfere with driving in Manitoba, Ontario, New Brunswick, Prince Edward Island and Newfoundland. Discretionary reporting was allowed in Nova Scotia, Quebec, Saskatchewan, Alberta and British Columbia (in B.C., the physician must report only if the patient continues to drive against medical advice). The two territories have mandatory reporting requirements.

\section{RESULTS}

Questionnaires (see Appendix) were sent to 510 neurologists of which 16 could not be located. Of the remaining 494 neurologists, 289 returned the completed questionnaire for an overall response rate of $59 \%$. The response rate was more than $50 \%$ in every province with the exception of $46 \%$ in Quebec (Table 1) suggesting that the survey was representative of opinion across the country. Although the $59 \%$ response is lower than the optimal rate of greater than $70 \%$ for most surveys, it can be considered high for a survey of physicians who, as a group, are notoriously poor responders. The reporting of different neurological conditions to the driving regulatory authorities by neurologists as a nationwide group varied considerably (Table 2). Patients with seizure disorders are reported almost always or most of the time by $50 \%$, significantly more than the $4 \%$ for stroke/TIA, $26 \%$ for dementia and $8 \%$ for other neurological conditions ( $\mathrm{p}<0.0001)$.

Table 3 shows responses to reporting of seizure disorders by neurologists who practice in provinces with mandatory $(n=$ $140)$ or discretionary $(n=149)$ reporting legislation. Those in provinces where reporting is mandatory are significantly more likely to report patients with seizures. When reporting is discretionary, only $19 \%$ of neurologists report always or most of the time, compared to $84 \%$ when reporting is mandatory ( $p<$ 0.001 ). In the other three categories of neurological disorders, reporting remained low and did not differ in mandatory and discretionary reporting environments.

When asked if they agreed with mandatory reporting of patients by physicians, $44 \%$ of Canadian neurologists indicated that they did and $56 \%$ did not (Table 4). However, there was also a significant difference $(p<0.0001)$ in the response to this question in provinces with and without mandatory reporting.

A minimum seizure free interval of three or six months before resuming driving was thought to be reasonable by $45 \%$ of neurologists and $6 \%$ felt there should be no minimum (Table 5). The opinions regarding seizure free interval were the same in mandatory and discretionary reporting provinces. Only $30 \%$ of neurologists thought the Canadian Medical Association Guidelines for seizures and driving were adequate and $5 \%$ did not know the guidelines. Written information regarding seizures and driving was provided to the patient by $16 \%$ of physicians. Table 6 shows the number of patients with seizures seen each month by the respondents. There were no differences in opinion for any of the questions in those who manage seizure disorders frequently, presumably including epileptologists, compared to other neurologists.

\begin{tabular}{llll}
\hline \multicolumn{3}{l}{ Table 1: Responses. } \\
\hline Total & $289 / 494$ & $=$ & $59 \%$ \\
Ontario & $119 / 182$ & $=$ & $65 \%$ \\
Quebec & $76 / 164$ & $=$ & $46 \%$ \\
Other* & $94 / 148$ & $=$ & $64 \%$ \\
\hline
\end{tabular}

$*>50 \%$ response in all other provinces

Table 2: Reporting of Patients with Neurological Disorders (p > 0.0001).

\begin{tabular}{lcccc} 
& Seizures & Stroke/TIA & Dementia & Other \\
\hline Almost always & $32 \%$ & 1 & 11 & 2 \\
Most of the time & 18 & 3 & 15 & 6 \\
About half the time & 5 & 9 & 13 & 10 \\
Some of the time & 24 & 41 & 34 & 40 \\
Almost never & 21 & 46 & 27 & 42 \\
\hline
\end{tabular}

Table 3: Seizure Reporting by Province $(\mathrm{p}>0.0001)$.

\begin{tabular}{lcc}
\hline & Mandatory $(\mathbf{n}=\mathbf{1 4 0})$ Discretionary $(\mathbf{n}=\mathbf{1 4 9})$ \\
\hline Almost always & $56 \%$ & 11 \\
Most of the time & 28 & 8 \\
About half the time & 5 & 6 \\
Some of the time & 5 & 40 \\
Almost never & 6 & 35 \\
\hline
\end{tabular}

Table 4: Physician Agreement with Mandatory Reporting $(\mathrm{p}>0.0001)$.

\begin{tabular}{lll}
\hline & Yes & No \\
\hline Overall $(\mathrm{n}=289)$ & $44 \%$ & $56 \%$ \\
Mandatory Reporting Provinces & $63 \%$ & $37 \%$ \\
Discretionary Reporting Provinces & $26 \%$ & $74 \%$ \\
\hline
\end{tabular}

Table 5: Minimum Seizure-free Interval.

\begin{tabular}{lr}
\hline & Overall \\
\hline 2 years or more & $3 \%$ \\
1 year & $46 \%$ \\
6 months & $35 \%$ \\
3 months & $10 \%$ \\
No minimum & $6 \%$ \\
\hline
\end{tabular}

Table 6: How Many Patients Seen with Seizures.

\begin{tabular}{cc}
\hline Monthly & $\%$ \\
\hline$>20$ & 22 \\
$10-20$ & 27 \\
$5-10$ & 28 \\
$0-5$ & 23 \\
\hline
\end{tabular}

-no differences across provinces or M vs. NM 


\section{Discussion}

There is a widely held belief that people with certain medical conditions, particularly seizures, should not drive because the assumption is they are more dangerous to themselves and to society than are members of the general public. Nationwide, $50 \%$ of neurologists report patients with seizures most of the time, which is in contrast to only $4 \%$ for stroke/TIA, $20 \%$ for dementia and $8 \%$ for other neurological disorders. Seizures appear to be perceived by neurologists to be in a different risk category than these other neurological conditions. This may, in part, relate to a common misconception that it is a legal requirement to specifically report seizures when in fact, provincial laws refer to any medical conditions which may interfere with driving.

The risk of having a motor vehicle accident is clearly influenced by a number of factors. For the general public, the accident rate per 100 licenced drivers in 1992 was $5.8 \%$ in Ontario ${ }^{1}$ and in 1993 was $3.2 \%$ in British Columbia. ${ }^{2} \mathrm{~A}$ reportable traffic accident occurred every 5.6 minutes in B.C. and an accident related injury every 11.2 minutes. Of all major contributing factors assigned to accidents, $83.4 \%$ were due to human error, $14.6 \%$ were related to environmental factors and $2 \%$ involved vehicle condition. The main contributing factors to accidents caused by human error were alcohol $63 \%$, driver inexperience $26 \%$ and sleep or fatigue $8 \%$. Only $3 \%$ related to medical conditions of which loss of consciousness made up about one-third. Seizures presumably would have been included in the latter group.

Since the first report of a motor vehicle accident as a result of a seizure in $1906^{3}$ studies have documented an increased risk of accidents amongst persons with epilepsy. Early surveys in Ohio ${ }^{4}$ and Washington ${ }^{5}$ both found a relative risk ratio of 1.5 for drivers with epilepsy compared to controls. In a study of 580 California drivers with epilepsy, Waller found the accident risk to be 1.95 compared to age matched controls or almost twice that of the general population. ${ }^{6}$ This compared to relative risks in diabetes of 1.78 , cardiovascular disease of 1.62 and substance abuse of 2.80. A review of British Columbia traffic accident statistics for the years 1985-1986 assessed the accident rate in the general population and in people with controlled epilepsy who had a valid driver's licence. During that time, the annualized accident risk in the 1394 licenced drivers with controlled epilepsy was $8.7 \%$ compared to $4.7 \%$ in the general population for a risk ratio of $1.8 .^{7} \mathrm{~A}$ contemporary study from Wisconsin ${ }^{8}$ looked retrospectively at accidents and traffic violations from 1985 to 1988 and found an estimated risk ratio for accidents of 1.33. The authors concluded that drivers with epilepsy have a slightly increased risk of traffic accidents compared to unaffected persons but that these risks were generally smaller than in previous studies reflecting the advances in diagnosis and management of epilepsy.

Although the overall risk of accident with seizures appears higher than in the general population, the risk of an individual with seizures will vary considerably considering on demographics, single vs. multiple seizures, diurnal vs. nocturnal occurrence, loss of awareness, etc. The consequences of loss of awareness during a generalized or complex partial seizure while driving are of obvious concern, but one problem with most studies of relative risk related to medical disability is that they sel- dom take into account important factors such as sex, age and driving exposure (amount of time spent driving). In fact, the relative risk of approximately 1.5 for driver's with epilepsy is similar to the relative risk of 1.4 when male driver's age 20 -24 years are compared to female drivers age 25-59 years in the general population. ${ }^{9}$ In order to keep our survey brief, we did not assess how these specific risk factors impact on neurologists' judgment.

Despite the evidence for increased risk of accident associated with epilepsy, the number of motor vehicle accidents related to seizures is small. In a 10 year study in the Netherlands ${ }^{10}$ only I in 11,000 accidents was due to seizures. Of 155 accidents related to seizures, $21 \%$ involved drivers who had been seizure free for more than two years and $12 \%$ were related to a first seizure. Twenty-six percent of drivers with previous seizures were not under treatment. Accidents were also relatively minor involving only the driver's car in $80 \%$ contrasting with $75 \%$ of accidents in the general population which involved two or more vehicles.

The issuing of a licence to drive is regulated by separate legislation in each of the ten Canadian provinces and the two territories. In every jurisdiction, the individual driver is required by law to report to the authorities any health problems which might interfere with driving; however, the regulations regarding physician reporting vary from province to province. In five provinces (ON, MB, NF, NB, PEI) and the two territories (YK, NWT), physicians are required by law to report to the Department of Motor Vehicles anyone with a medical condition which might impair driving ability. For example, in Ontario, the Highway Traffic Act states "every legally qualified medical practitioner shall report ... every person ... who, in the opinion of such medical practitioners is suffering from a condition that may make it dangerous for such person to operate a motor vehicle". In five provinces (PQ, NS, SK, AB, BC) the law stipulates that it is at the discretion of the physician whether to report a patient's medical condition to the Transportation Ministry with the exception of certain commercial licences in Nova Scotia and the caveat that in British Columbia, the physician is required to report only if the patient continues to drive against medical advice. Canadian legislation in this regard is in contrast to the United States where reporting of patients with medical conditions is at the discretion of the physician in 46 of 52 states.

In order to assist physicians, including those who sit on review panels for the Ministries of Transportation to determine medical fitness to drive, guidelines have been established by the Canadian Medical Association, the Canadian Council on Motor Transportation Administration which sets the National Safety Code and some of the provincial medical associations. In addition to these guidelines which are distinct from the laws regulating driving, recommendations have also been made by the Canadian Medical Protective Association, various epilepsy associations and Ministries of Transportation. It is thus, not surprising that there appears to be a certain amount of confusion among physicians about what the law requires and what the guidelines state.

In regard to the issue of epilepsy and driving, Dr. Fred Andermann observed in 1988 that in Quebec "there seems to be great variation in the approaches of neurologists to this problem"." As documented by our survey, this is even more clearly the case nationwide. A minority of neurologists (44\%) favoured mandatory reporting requirements nationwide but when this was 
broken down by region, those practising in provinces with mandatory reporting legislation were much more likely to support such laws than those who practice under discretionary reporting legislation (63\% vs. $26 \%$ ). It is thus, not surprising that in provinces with mandatory reporting laws, $84 \%$ of neurologists report patients with seizures to the Ministry of Transportation most of the time compared to only 19\% who do so in discretionary reporting provinces. These findings appear to reflect a fundamental difference in opinion as to whether the onus should be on the physician or the state in determining if an individual with a medical disorder should continue to drive. Even neurologists who see many people with epilepsy and who may arguably be more sensitive to the issues regarding epilepsy and driving were no more likely to favour discretionary reporting than their colleagues who see few epilepsy patients.

A report by the International League Against Epilepsy/International Bureau for Epilepsy Commission on driver's licencing in $1992^{12,13}$ stated that "the widely held view that physicians should not generally be required by law to notify licencing or other authorities of their patients' epilepsy is endorsed" and a consensus statement from the American Academy of Neurology, American Epilepsy Society and Epilepsy Foundation of America in $1994^{14}$ supported this view indicating there was "unanimous agreement that physicians should not be required to report their patients". However, both of these documents went on to say that doctors should be professionally obliged to inform patients of the nature of their condition, the risks involved in driving and the legal requirements for individuals to report their condition. If the patient continues to drive against medical advice, then the physician should be "authorized" to report. This is similar to the British Columbia legislation which legally requires doctors to report only under the latter conditions. Many neurologists advocate this more lenient approach because they have observed the devastating effect loss of driving privileges can have on individuals already compromised socioeconomically by their medical condition. In Canada, doctors are protected by law from breach of confidentiality lawsuits if they do report a patient under any circumstances. On the other hand, in provinces where reporting is mandatory, physicians have been found liable for failing to report patients with epilepsy who subsequently had an accident.

There is no clear evidence that mandatory reporting of people with medical conditions, particularly seizures increases traffic safety. In fact, the one study of 112 epileptic drivers which assessed accident risk in those known to the Ministry of Transportation and those who had not been reported showed no difference in the accident rate in the two groups. The accident risk ratio compared to the general population was actually higher at 1.5 in the drivers known to the authorities compared to 1.1 in the other group. ${ }^{15}$ No studies have yet been done to indicate that the risk of motor vehicle accidents caused by medical conditions is any greater in Canadian provinces with discretionary compared to mandatory reporting laws. An argument can even be made that compulsory reporting by physicians could be detrimental to individual and public safety since such laws may lead to a breakdown in the doctor patient relationship if the patient fears that information provided to his physician would be used against him to deny a driver's licence. Thus patients may withhold important facts about their condition from their doctor or deny themselves treatment by avoiding medical atten- tion altogether. This is supported by the results of a survey of drivers with epilepsy in Oregon ${ }^{16}$ which revealed that in a mandatory reporting environment, patients would be four times as likely ( $16 \%$ vs. $4 \%$ ) not to inform their physicians of seizure activity, compared to how they would respond in a discretionary reporting system. This study also revealed that twice as many $(17 \%$ vs. $9 \%)$ would drive illegally with a suspended licence if reported by their physicians compared to self-report.

Canadian neurologists vary in their opinion about how long the duration from the last seizure should be before resuming driving. Only $49 \%$ support the current Canadian recommendation of at least a one year seizure free interval which has already been reduced from the previously recommended two year interval. This reflects a general trend toward shorter intervals as does a recent recommendation from the American Consensus statement that the minimum seizure free interval be three months ${ }^{14}$ since most seizures recur within that time. This and other recommendations within the various medical guidelines regarding epilepsy and driving require regular reassessment supported by further research on the factors which influence accident risk and the impact of driving restrictions in people with medical conditions.

\section{ACKNOWLEDGEMENT}

The authors thank the Canadian League Against Epilepsy, the Epilepsy Association of Metro-Toronto and Glaxo Wellcome Canada for their support.

\section{REFERENCES}

1. Ontario Road Safety Annual Report. Ministry of Transportation; 1992.

2. Traffic Statistics. Province of British Columbia, Ministry of Transportation and Highways; 1993.

3. Thalwitzer F. Epileptiker als Autofahrer. Munch Med Wochenschr 1906; 37: 1818

4. Keys JB, Martin CJ, Barrow EL, Fabing HD. The epileptic automobile driver in Ohio. Ohio State Med J 1961; 57: 1127-1131.

5. Crancer AJ, McMurray L. Accident and violation rates of Washington's medically restricted drivers. JAMA 1968; 205: 272-276.

6. Waller JA. Chronic medical conditions and traffic safety. N Engl J Med 1965; 273: 1413-1420.

7. Jones MW. Epilepsy and driving. BC Med J 1991; 33: 392-394.

8. Hansotia P, Broste SK. The effect of epilepsy or diabetes mellitus on the risk of automobile accidents. N Engl J Med 1991; 324: 22-26.

9. Smiley A, Lee-Gosselin M, Chipman M, MacGregor C. A study of the amount and type of driving done by Ontario drivers. Report of the Ministry of Transportation in Ontario. 1991.

10. Van der Lug PJM. Traffic accidents and epilepsy. Epilepsia 1975; 16: 747-751.

11. Andermann F, Remillard GM, Zifkin BG, Trottier AG, Drouin P. Epilepsy and driving. Can J Neurol Sci 1988; 15: 371-377.

12. Parsonage $M$, et al. Epilepsy and Driving Licence Regulations. The ILAE/IBE Commission on Drivers Licencing; 1992.

13. Fisher RS, Parsonage M, Beaussart $M$, et al. Epilepsy and driving: an international perspective. Epilepsia 1994; 35: 675-684.

14. American Academy of Neurology, American Epilepsy Society, Epilepsy Foundation of America. Consensus statements, sample statutory provisions and model regulations regarding driver licensing and epilepsy. Epilepsia 1994; 35: 696-705.

15. Popkin CL, Waller PF. Epilepsy and driving in North Carolina: an exploratory study. Accident Analysis and Prevention 1988; 21: 389-393.

16. Salinsky MC, Wegener K, Sinnema F. Epilepsy, driving laws and patient disclosure to physicians. Epilepsia 1992; 33: 469-472. 
1. In what Province do you practice?

2. Please indicate, by circling the appropriate number, how often you report patients with the following conditions:

$1=$ almost never $2=$ some of the time; $3=$ about half the time; $4=$ most of the time; $5=$ almost always

$\begin{array}{llllll}\text { Seizures } & 1 & 2 & 3 & 4 & 5 \\ \text { Stroke or TIA } & 1 & 2 & 3 & 4 & 5 \\ \text { Dementia } & 1 & 2 & 3 & 4 & 5 \\ \text { Other Neurological Conditions } & 1 & 2 & 3 & 4 & 5\end{array}$

3. How many patients with seizures do you see each month on average?
$0-5$
$5-10$
$10-20$
$>20$

4. Do you agree with mandatory reporting by physicians?

Yes

No

*5. Should ability to drive be determined primarily by:
a) individual assessment by treating physician
b) individual assessment by Ministry of Transportation
c) other, please specify:

6. In your opinion, what is the minimum length of time a patient should be seizure free before driving?

No minimum ; 3 months ; 6 months ; 1 year ; 2 years ; $2+$ years

7. Do you provide any written information to patients about seizures and driving?

Yes

No

None available

*8. Which statement best describes your attitudes towards the current CMA guidelines as they relate to epilepsy and driving?
a) do not require any significant revision.
b) are mostly adequate but need changes in specific areas.
c) are mostly inadequate and require significant changes.

*These questions were considered to be too vague to use in the final analysis. The responses were 5a) $30 \%$, b) $47 \%$, c) $23 \%$; 8 a) $30 \%$, b) $54 \%$, c) $11 \%$ (5\% wrote they did not know the guidelines). 